\title{
Association of anti-nuclesome and anti C1q antibodies with lupus nephritis in an Egyptian cohort of patients with systemic lupus erythematosus
}

\author{
Imman Mokhtar Metwally ${ }^{1}$, Nahla Naeem Eesa ${ }^{1 *}$, Mariam Halim Yacoub² and Rabab Mahmoud Elsman ${ }^{3}$
}

\begin{abstract}
Introduction: Anti-nucleosome and anti-C1q antibodies demonstrated an association with the development of glomerulonephritis in systemic lupus erythematosus (SLE). Some investigators have proposed that monitoring anti$\mathrm{Clq}$ and anti-nucleosome antibodies might be valuable for making predictions about lupus nephritis (LN) and assessment of disease activity as a non-invasive biological marker of renal disease.
\end{abstract}

Objectives: The current study was proposed to investigate the presence of anti-C1q and anti-nucleosome antibodies in the sera of Egyptian patients with SLE and their association with LN.

Methods: Eighty patients with SLE were included. Patients were classified into, a LN group including 40 cases with active LN (based on the results of renal biopsy and renal SLEDAI $\geq 4$ ) and a non renal SLE group including 40 patients (with no clinical or laboratory evidence of renal involvement that were attributed in the past or present to SLE). They were subjected to full medical history taking, clinical examination, routine laboratory investigations, measurement of antinuclear antibody (ANA), anti-ds DNA, anti-C1q \& anti-nucleosome antibodies.

Results: Anti-C1q antibody showed a statistically significant association with the presence of vasculitis and nephritis while anti-nucleosome antibody didn't show a significant association with the presence of any clinical features. Double positivity of anti-nucleosome and anti-C1q antibodies showed a statistically significant association with the presence of vasculitis and photosensitivity, high ECLAM score, elevated ESR, low serum albumin and low C3 levels.

Conclusion: Serum anti-C1q antibody has a significant association with LN while double positive antibodies have a significant association with vasculitis and low C3 levels in Egyptian patients with SLE.

Keywords: Systemic lupus erythematosus, Lupus nephritis, Anti-C1q antibody, Anti-nucleosome antibody

\section{Introduction}

Renal involvement in systemic lupus erythematosus (SLE), known as lupus nephritis (LN), is a common and serious complication and a major predictor of poor outcome with reports of 5-year survival with treatment ranging from 46 to $95 \%$ [1]. Early diagnosis and initiation of immunosuppressive treatment is critical to improve outcome of patients with LN and hence long-term survival in SLE [2]. However, the insidious onset and fluctuating

\footnotetext{
* Correspondence: nahlanaeem@gmail.com; nahla.ali@kasralainy.edu.eg ${ }^{1}$ Rheumatology and Rehabilitation Department, Faculty of Medicine, Cairo University, Cairo, Egypt

Full list of author information is available at the end of the article
}

nature of LN can make early detection and follow-up very difficult $[3,4]$. Being an invasive, painful and risky procedure, the utility of renal biopsy as the first approach to patients with suspected LN is still controversial [5]. Renal biopsy remains the gold standard for the evaluation of LN disease activity. Renal biopsy is important to define the nature of renal involvement. Mechanisms other than immune-complex mediated glomerulonephritis can result in renal injury and require a different approach to management [6]. A more comprehensive picture of kidney pathology may be desirable as therapy of LN develops beyond the currently available non-targeted immunosuppressives to interventions that 
focus on specific immune pathways [7]. Up to date, the available literature does not allow us to state that omitting renal biopsy in the diagnostic and therapeutic routine brings more advantages than threats [5]. A reliable clinical biomarker that can forecast LN well before thresholds of proteinuria, renal function and urine sediment that signal clinical flare are reached would be a valuable tool $[8,9]$. There are several autoantibodies that required attention in LN, including their use in diagnosis and monitoring, and their role in the pathogenesis [10]. Anti-nucleosome and anti-C1q antibodies demonstrated an association with the development of glomerulonephritis in SLE [11]. It has been suggested that autoantibodies to C1q were found to be elevated in the sera of SLE patients and are closely associated with renal involvement [12]. Some investigators have proposed that monitoring anti-C1q might be valuable for the clinical management of SLE patients as a non-invasive biological marker of renal disease [13]. A Brazilian study on SLE patients confirmed the association of anti-C1q antibodies with nephritis and disease activity [14]. Another autoantibody that has been proposed to be linked to the occurrence of glomerulonephritis in lupus is antinucleosome antibody [15]. Nucleosomes are generated during cell apoptosis by cleavage of the chromatin by endonucleases. Studies have shown that the clearance of apoptotic cells by macrophages in patients with SLE is impaired. This leads to decreased clearance of nucleosome [16]. Anti-nucleosome antibodies could be a useful parameter for early diagnosis and follow-up of SLE with nephritis [17]. The current work was carried out to investigate the association of both anti-nucleosome and anti-C1q antibodies with the occurrence of lupus nephritis.

\section{Patients and methods Study population}

This study was conducted on eighty patients with SLE diagnosed according to the American College of Rheumatology (ACR) 1997 revised criteria for the classification of SLE [18]. Subjects were recruited from the Rheumatology and Rehabilitation Department, Faculty of Medicine, Cairo University hospitals and Rheumatology clinic of Helwan University Hospital from December 2016 to December 2017. An Informed consent was obtained from all patients and the study was approved by the local ethics committee.

Patients were classified into two groups, group (I) which included 40 cases with active LN [based on the results of kidney biopsy and renal systemic lupus erythematosus disease activity index (rSLEDAI) $\geq 4$ ] and group (II) which included 40 age matched SLE patients without LN [with no evidence of major renal manifestations that were attributed in the past or present to SLE disease and with normal serum creatinine and urine sediment].

\section{Methods}

All SLE patients were subjected to full history taking, general examination, cardio pulmonary, abdominal, neurological and locomotor systems examination. Peripheral blood was obtained within 3 days before renal biopsy for measurement of autoantibodies, complete blood count $(\mathrm{CBC})$, complement $\mathrm{C} 3$ and $\mathrm{C} 4$ levels, erythrocyte sedimentation rate (ESR), blood urea nitrogen (BUN), serum albumin, and creatinine. Urine analysis and protein quantification in $24 \mathrm{~h}$ urine samples were performed for all patients. ANA were determined by indirect immunofluorescence (Hemagen Diagnostics, USA), titres of 1:160 were taken as a cut off value. Anti-dsDNA were done by Crithidia Luciliae indirect immunofluorescence test (CLIFT). Serum C3 and C4 levels by nephelometry (Beckman, USA). Anti C1q and antinucleosome IgG antibodies were tested in sera using Enzyme Linked Immunosorbent Assay (ELISA) [19, 20]. (According to the manufacturers' instructions from Orgentic Diagnostika $\mathrm{GmbH}$ ). Cut off values were $\geq 10 \mathrm{u} / \mathrm{ml}$ for Anti C1q and $\geq 20 \mathrm{u} / \mathrm{ml}$ for antinucleosome antibodies.

Renal pathology was classified according to the revised International Society of Nephrology and Renal Pathology Society (ISN/RPS) classification [21].

\section{Assessment of disease activity}

Disease activity was assessed using The European Consensus Lupus Activity Measurement (ECLAM) [22]. A global activity score which assesses disease activity within the past month. It comprises 15 weighted clinical and serological items with a theoretically possible range of $0-10$, with 0 being no disease activity.

\section{Statistical analysis}

Data was collected, tabulated and statistically analyzed using Statistical package for social science (SPSS) software version 15. Measurement of data consistent with normal distribution was expressed as mean \pm SD. Measurement of categorical variables was expressed using the odds ratio and 95\% confidence interval. Statistical differences between groups were tested using Chi Square test for qualitative variables, Student's $\mathrm{T}$ test between 2 groups for quantitative normally distributed variables while Nonparametric Mann-Whitney test and Kruskal-Wallis test were used for quantitative variables which are not normally distributed. Correlations were done to test for linear relations between variables. $P$-values less than 0.05 were considered statistically significant.

\section{Results}

Clinical and laboratory features among patient groups

Eighty Egyptian patients with SLE, 40 with LN (group

I) and 40 without (group II) were included in this 
study. Active LN patients were receiving pulse methylprednisolone, cyclophosphamide and mycophenolate mofetil while those without LN were maintained on oral prednisolone, hydroxychloroquine and azathioprine. Clinical features did not show a significant difference between the two groups. However statistically significant differences were found between both groups in the following variables: ECLAM score, serum albumin, serum creatinine, low C3 \& C4 and anti-C1q antibody positivity. Detailed comparisons between groups are presented in Table 1.
Relationship between anti-nucleosome antibodies and other disease parameters among study groups

Anti-nucleosome antibody was positive in 49 (61.25\%) patients of the 80 SLE patients. $24(60 \%)$ patients in group I and in 25 (62.5\%) patients in group II. Clinical features, activity assessment by ECLAM and renal histopathology did not show a significant difference between patients with positive and those with negative anti-nucleosome antibody. However serum creatinine was statistically significantly lower among patients with positive anti-nucleosome antibody $(t=2.11, P<0.05)$. (Tables 2 and 3 ).

Table 1 Comparison between both SLE groups (with and without LN) regarding demographic, laboratory and clinical characteristics

\begin{tabular}{|c|c|c|c|c|c|}
\hline $\begin{array}{l}\text { Parameter } \\
\text { mean } \pm \text { SD or } n(\%)\end{array}$ & & $\begin{array}{l}\text { Group I } \\
(n=40)\end{array}$ & $\begin{array}{l}\text { Group II } \\
(n=40)\end{array}$ & $t / x^{2}$ & $P$ value \\
\hline \multirow[t]{3}{*}{ Demographic features } & Age (year) & $29.0 \pm 7.2$ & $32.5 \pm 9.4$ & 1.756 & 0.083 \\
\hline & Disease duration (year) & $4.4 \pm 3.7$ & $6.8 \pm 5.6$ & 2.280 & 0.025 \\
\hline & Male/ Female & $6(15) / 34(85)$ & $1(2.5) / 39(97.5)$ & 3.914 & 0.048 \\
\hline \multirow[t]{13}{*}{ Clinical features } & Arthritis & $34(85.0)$ & $38(95.0)$ & 2.200 & 0.136 \\
\hline & Malar rash & $25(62.5)$ & $25(62.5)$ & 0.00 & 1.000 \\
\hline & Fever & $22(55.0)$ & $17(42.5)$ & 1.251 & 0.263 \\
\hline & Pleurisy & $21(52.5)$ & $21(52.5)$ & 0.000 & 1.000 \\
\hline & Oral ulcers & $17(42.5)$ & $21(52.5)$ & 0.802 & 0.370 \\
\hline & Alopecia & $17(42.5)$ & $17(42.5)$ & 0.000 & 1.000 \\
\hline & Photosensitivity & $13(32.5)$ & $18(45.0)$ & 1.317 & 0.251 \\
\hline & Vasculitis & $10(25.0)$ & $4(10.0)$ & 3.117 & 0.077 \\
\hline & APS & $10(25.0)$ & $9(22.5)$ & 0.069 & 0.793 \\
\hline & Neurological manifestations & $9(22.5)$ & $11(27.5)$ & 0.267 & 0.606 \\
\hline & Pericarditis & $6(15.0)$ & $4(10.0)$ & 0.457 & 0.499 \\
\hline & Discoid rash & $2(5.0)$ & $4(10.0)$ & 0.721 & 0.396 \\
\hline & Myositis & $1(2.5)$ & $0(0.0)$ & 1.013 & 0.314 \\
\hline ECLAM & & $4.7 \pm 2.3$ & $2.9 \pm 1.4$ & 4.326 & $<0.001$ \\
\hline \multirow[t]{8}{*}{ Laboratory features } & ESR (mm/1st hour) & $54.6 \pm 32.4$ & $41.7 \pm 26.9$ & 1.942 & 0.056 \\
\hline & Serum creatinine $(\mu \mathrm{mol} / \mathrm{L})$ & $1.0 \pm 0.7$ & $0.6 \pm 0.2$ & 2.79 & 0.008 \\
\hline & Serum albumin (g/dl) & $3.6 \pm 0.6$ & $4.1 \pm 0.7$ & 3.895 & $<0.001$ \\
\hline & $24 \mathrm{~h}$ urinary proteins (g/24 h) & $2 \pm 1.7$ & & & \\
\hline & Low C3 $<90$ & $26(65.0)$ & $10(25.0)$ & 12.929 & $<0.001$ \\
\hline & Low $C 4<10$ & $17(42.5)$ & $2(5.0)$ & 15.531 & $<0.001$ \\
\hline & Anti-nucleosome antibody positivity & $24(60.0)$ & $25(62.5)$ & 0.053 & 0.818 \\
\hline & Anti-C1q antibody positivity & $23(57.5)$ & $11(27.5)$ & 7.366 & 0.007 \\
\hline \multirow[t]{7}{*}{ Renal biopsy } & Lupus nephritis class I & $0(0)$ & - & - & - \\
\hline & Lupus nephritis class II & $5(12.5)$ & - & - & - \\
\hline & Lupus nephritis class III & $13(32.5)$ & - & - & - \\
\hline & Lupus nephritis class IV & $11(27.5)$ & - & - & - \\
\hline & Lupus nephritis class V & $3(7.5)$ & - & - & - \\
\hline & Lupus nephritis class II- III & $6(15)$ & - & - & - \\
\hline & Lupus nephritis class II \& V & $2(5)$ & - & - & - \\
\hline
\end{tabular}


Table 2 Relationship between anti-nucleosome antibody and other disease parameters among patients under study

\begin{tabular}{|c|c|c|c|c|c|}
\hline \multicolumn{2}{|c|}{ Variable $\mathrm{n}(\%)$ or mean $\pm \mathrm{SD}$} & \multirow{2}{*}{$\begin{array}{l}\text { Positive } \\
\text { Anti-nucleosome }(n=49) \\
42(85.7)\end{array}$} & \multirow{2}{*}{$\begin{array}{l}\text { Negative } \\
\text { Anti-nucleosome }(n=31) \\
30(96.8)\end{array}$} & \multirow{2}{*}{$\begin{array}{l}t / x^{2} \\
2.581\end{array}$} & \multirow{2}{*}{$\begin{array}{l}P \text { value } \\
0.108\end{array}$} \\
\hline Clinical features & Arthritis & & & & \\
\hline & Pleurisy & $28(57.1)$ & $14(45.2)$ & 1.093 & 0.296 \\
\hline & Fever & $27(55.1)$ & $12(38.7)$ & 2.042 & 0.153 \\
\hline & Malar rash & $27(55.1)$ & $23(74.2)$ & 2.953 & 0.086 \\
\hline & Oral ulcers & $24(49.0)$ & $14(45.2)$ & 0.111 & 0.739 \\
\hline & Alopecia & $22(44.9)$ & $12(38.7)$ & 0.298 & 0.585 \\
\hline & Photosensitivity & 15 (30.6) & $16(51.6)$ & 3.528 & 0.060 \\
\hline & Neurologic manifestations & $13(26.5)$ & $7(22.6)$ & 0.158 & 0.691 \\
\hline & APS & $12(24.5)$ & $7(22.6)$ & 0.038 & 0.845 \\
\hline & Vasculitis & $11(22.4)$ & $3(9.7)$ & 2.145 & 0.143 \\
\hline & Pericarditis & $8(16.3)$ & $2(6.5)$ & 1.693 & 0.193 \\
\hline & Discoid rash & $4(8.2)$ & $2(6.5)$ & 0.080 & 0.777 \\
\hline & Myositis & $1(2.0)$ & $0(0.0)$ & 0.641 & 0.423 \\
\hline & Nephritis & $24(49 \%)$ & $16(51.6)$ & 2.937 & 0.230 \\
\hline ECLAM & & $4.1 \pm 2.2$ & $3.3 \pm 1.8$ & 1.805 & 0.075 \\
\hline \multirow[t]{5}{*}{ Laboratory features } & ESR (mm/1st hour) & $51.0 \pm 30.7$ & $43.7 \pm 29.7$ & 1.051 & 0.296 \\
\hline & Serum creatinine $(\mu \mathrm{mol} / \mathrm{L})$ & $0.7 \pm 0.3$ & $1.0 \pm 0.8$ & 2.110 & 0.038 \\
\hline & Serum albumin (g/dl) & $3.8 \pm 0.7$ & $4.0 \pm 0.7$ & 1.207 & 0.232 \\
\hline & Low C3 < 90 (mg/dl) & $25(51.0)$ & $11(35.5)$ & 1.852 & 0.174 \\
\hline & Low C4 < $10(\mathrm{mg} / \mathrm{dl})$ & $11(22.4)$ & $8(25.8)$ & 0.118 & 0.731 \\
\hline
\end{tabular}

APS: Antiphospholipid syndrome, ESR: Erythrocyte sedimentation rate, ECLAM: European Consensus Lupus Activity Measurement

\section{Relationship between anti-C1q antibodies and other disease parameters among study groups}

Anti-C1q antibody was positive in $34(42.5 \%)$ of the 80 SLE patients. $23(57.5 \%)$ patients in group I and in 11 $(27.5 \%)$ patients in group II. Positivity of anti-C1q antibody showed a statistically significant association with the presence of vasculitis and nephritis, elevated ESR, low serum albumin and low C3 and C4 levels. However, activity assessment by ECLAM and renal histopathology did not show a significant difference between patients with positive and those with negative anti-C1q antibody. (Tables 4 \& 5).

\section{Double positivity of anti-nucleosome and anti-C1q antibodies}

Both anti-nucleosome and anti-C1q antibodies were positive in $22(27.5 \%)$ patients. $15(37.5 \%)$ patients in group I and 7 (17.5\%) patients in group II. However both antibodies were negative in $19(23.75 \%)$ patients. 8 (20\%) patients in group I and $11(27.5 \%)$ patients in group II. Double positivity of anti-nucleosome and anti-C1q antibodies anti-C1q antibody showed a statistically significant association with the presence of vasculitis and photosensitivity, high ECLAM score, elevated ESR, low serum albumin and low C3 levels. However,

Table 3 Relationship between anti-nucleosome antibody and renal histopathology in patients with LN.

\begin{tabular}{|c|c|c|c|c|}
\hline Renal biopsy, n (\%) & $\begin{array}{l}\text { Positive anti-nucleosome } \\
\text { antibody } \\
(N=24)\end{array}$ & $\begin{array}{l}\text { Negative anti-nucleosome antibody } \\
(N=16)\end{array}$ & $x^{2}$ & $P$ value \\
\hline Lupus nephritis class I & 0 & $0(0)$ & 0.000 & 0.000 \\
\hline Lupus nephritis class II & $2(8.3)$ & $3(18.8)$ & 0.952 & 0.329 \\
\hline Lupus nephritis class III & $5(20.8)$ & $8(50)$ & 2.401 & 0.121 \\
\hline Lupus nephritis class II -III & $5(20.8)$ & $1(6.3)$ & 1.601 & 0.206 \\
\hline Lupus nephritis class IV & $9(37.5)$ & $2(12.5)$ & 3.009 & 0.083 \\
\hline Lupus nephritis class V & $2(8.3)$ & $1(6.3)$ & 0.060 & 0.806 \\
\hline Lupus nephritis class II \& V & $1(4.2)$ & $1(6.3)$ & 0.088 & 0.767 \\
\hline
\end{tabular}


Table 4 Relationship between anti-C1q antibody and other disease parameters among patients under study

\begin{tabular}{|c|c|c|c|c|c|}
\hline $\begin{array}{l}\text { Variable } \\
\mathrm{n}(\%) \text { or mean } \pm \mathrm{SD}\end{array}$ & & $\begin{array}{l}\text { Positive } \\
\text { Anti-C1q } \\
(n=34)\end{array}$ & $\begin{array}{l}\text { Negative } \\
\text { Anti-C1q } \\
(n=46)\end{array}$ & $t / x^{2}$ & $P$ value \\
\hline \multirow[t]{14}{*}{ Clinical features } & Arthritis & $31(91.2)$ & $41(89.1)$ & 0.091 & 0.763 \\
\hline & Pleurisy & $15(35.7)$ & $27(58.7)$ & 1.666 & 0.197 \\
\hline & Fever & $19(55.9)$ & $20(43.5)$ & 1.204 & 0.273 \\
\hline & Malar rash & $20(58.8)$ & $30(65.2)$ & 0.341 & 0.559 \\
\hline & Oral ulcers & $17(50.0)$ & $21(45.7)$ & 0.148 & 0.700 \\
\hline & Alopecia & $13(38.2)$ & $21(61.8)$ & 0.440 & 0.507 \\
\hline & Photosensitivity & $11(32.4)$ & $20(43.5)$ & 1.020 & 0.313 \\
\hline & Neurologic manifestations & $6(17.6)$ & $14(30.4)$ & 1.705 & 0.192 \\
\hline & APS & $6(17.6)$ & $13(28.3)$ & 1.216 & 0.270 \\
\hline & Vasculitis & $10(29.4)$ & $4(8.7)$ & 5.811 & 0.016 \\
\hline & Pericarditis & $5(14.7)$ & $5(10.9)$ & 0.263 & 0.608 \\
\hline & Discoid rash & $4(11.8)$ & $2(4.3)$ & 1.550 & 0.213 \\
\hline & Myositis & $0(0.0)$ & $1(2.2)$ & 0.748 & 0.387 \\
\hline & Nephritis & $23(67.6)$ & $17(37.0)$ & 7.366 & 0.007 \\
\hline ECLAM & & $4.2 \pm 1.9$ & $3.5 \pm 2.2$ & 1.572 & 0.120 \\
\hline \multirow[t]{5}{*}{ Laboratory features } & ESR (mm/1st hour) & $57.7 \pm 32.5$ & $41.1 \pm 26.8$ & 2.500 & 0.015 \\
\hline & Serum creatinine $(\mu \mathrm{mol} / \mathrm{L})$ & $0.9 \pm 0.7$ & $0.8 \pm 0.3$ & 0.643 & 0.500 \\
\hline & Serum albumin (g/dl) & $3.6 \pm 0.5$ & $4.0 \pm 0.8$ & 2.677 & 0.009 \\
\hline & Low C3 < 90 (mg/dl) & $20(58.8)$ & $16(34.8)$ & 4.565 & 0.033 \\
\hline & Low C4 < 10 (mg/dl) & $12(35.3)$ & $7(15.2)$ & 4.351 & 0.037 \\
\hline
\end{tabular}

APS Antiphospholipid syndrome, ESR Erythrocyte sedimentation rate, ECLAM European Consensus Lupus Activity Measurement

renal histopathology did not show a significant difference between patients with double positive and those with double negative antibodies. (Table 6).

\section{Predictors of lupus nephritis}

Multivariate analysis demonstrated that a low $\mathrm{C} 4$ complement level was most highly predictive of the presence of lupus nephritis, with a relative risk of 14.04 and a $P$ value of $<0.001$. A low C3 complement level was the next most significant factor, with a relative risk of 5.57 and a $P$ value of $<0.001$. In addition, the presence of anti-C1q antibody provided a significant predictive value with a relative risk of 3.60 and a $P$ value of 0.007 (Table 7).

\section{Discussion}

There is a prevailing need for validated biomarkers that can diagnose active organ involvement during SLE disease flares. Lupus nephritis (LN) is a common major organ manifestation and a main cause of morbidity and mortality. The diagnosis of LN has an important clinical implication in guiding treatment of SLE [23]. Some investigators have proposed that monitoring anti-C1q and anti-nucleosome antibodies might be valuable for making predictions about lupus nephritis and assessment of

Table 5 Relationship between anti-C1q antibody and renal histopathology in patients with LN

\begin{tabular}{|c|c|c|c|c|}
\hline Renal biopsy, n (\%) & $\begin{array}{l}\text { Positive anti-C1q } \\
(N=23)\end{array}$ & $\begin{array}{l}\text { Negative anti-C1q } \\
(N=17)\end{array}$ & $x^{2}$ & $P$ value \\
\hline Lupus nephritis class I & $0(0)$ & $0(0)$ & 0.000 & 0.000 \\
\hline Lupus nephritis class II & $2(8.7)$ & $3(17.6)$ & 0.716 & 0.397 \\
\hline Lupus nephritis class III & $9(39.1)$ & $4(23.5)$ & 0.589 & 0.443 \\
\hline Lupus nephritis class II- III & $5(21.7)$ & $1(5.9)$ & 1.928 & 0.165 \\
\hline Lupus nephritis class IV & $4(17.4)$ & $7(41.2)$ & 2.774 & 0.096 \\
\hline Lupus nephritis class V & $3(13)$ & $0(0)$ & 2.397 & 0.122 \\
\hline Lupus nephritis class II \& V & $0(0)$ & $2(11.8)$ & 2.848 & 0.091 \\
\hline
\end{tabular}


Table 6 Relationship between double positivity of anti-nuclesome and anti-C1q antibodies and other disease parameters among patients under study

\begin{tabular}{|c|c|c|c|c|c|}
\hline $\begin{array}{l}\text { Variable } \\
\mathrm{n}(\%) \text { or mean } \pm \mathrm{SD}\end{array}$ & & $\begin{array}{l}\text { Double Positive } \\
(n=22)\end{array}$ & $\begin{array}{l}\text { Double Negative } \\
(n=19)\end{array}$ & $t / x^{2}$ & $P$ value \\
\hline \multirow[t]{14}{*}{ Clinical features } & Arthritis & $19(86.4)$ & $18(94.7)$ & 0.812 & 0.368 \\
\hline & Pleurisy & $14(63.6)$ & $13(68.4)$ & 0.104 & 0.747 \\
\hline & Fever & $14(63.6)$ & $7(36.8)$ & 2.930 & 0.087 \\
\hline & Malar rash & $11(50.0)$ & $14(73.7)$ & 2.403 & 0.121 \\
\hline & Oral ulcers & $12(54.5)$ & $9(47.4)$ & 0.21 & 0.647 \\
\hline & Alopecia & $10(45.5)$ & $9(47.4)$ & 0.015 & 0.902 \\
\hline & Photosensitivity & $6(27.3)$ & $11(57.9)$ & 3.939 & 0.047 \\
\hline & Neurologic manifestations & $5(22.7)$ & $6(31.6)$ & 0.407 & 0.524 \\
\hline & APS & $5(22.7)$ & $6(31.6)$ & 0.407 & 0.524 \\
\hline & Vasculitis & $8(36.4)$ & $1(5.3)$ & 5.756 & 0.016 \\
\hline & Pericarditis & $5(22.7)$ & $2(10.5)$ & 1.072 & 0.301 \\
\hline & Discoid rash & $3(13.6)$ & $1(5.3)$ & 0.812 & 0.368 \\
\hline & Myositis & $0(0.0)$ & $0(0.0)$ & -- & -- \\
\hline & Nephritis & $15(68.18)$ & $8(42.1)$ & 3.051 & 0.217 \\
\hline ECLAM & & $4.6 \pm 2.1$ & $3.1 \pm 2.1$ & 2.254 & 0.030 \\
\hline \multirow[t]{6}{*}{ Laboratory features } & ESR (mm/1 $1^{\text {st }}$ hour) & $59.6 \pm 32.3$ & $37.0 \pm 25.1$ & 2.471 & 0.018 \\
\hline & Serum creatinine $(\mu \mathrm{mol} / \mathrm{L})$ & $0.7 \pm 0.3$ & $0.9 \pm 0.4$ & 1.443 & 0.157 \\
\hline & Serum albumin (g/dl) & $3.6 \pm 0.5$ & $4.2 \pm 0.8$ & 2.960 & 0.005 \\
\hline & Low C3 < 90 (mg/dl) & $14(63.6)$ & $5(26.3)$ & 5.711 & 0.017 \\
\hline & Low C4 < 10 (mg/dl) & $7(31.8)$ & $5(15.8)$ & 1.420 & 0.233 \\
\hline & 24 hours urinary proteins (gm/24hrs) & $2.1 \pm 2.0$ & $1.6 \pm 1.5$ & 0.606 & 0.551 \\
\hline
\end{tabular}

APS: Antiphospholipid syndrome, ESR: Erythrocyte sedimentation rate, ECLAM: European Consensus Lupus Activity Measurement

disease activity as a non-invasive biological marker of renal disease [13].

In this study we investigated the association of anti-nucleosome and anti-C1q antibodies with the development of lupus nephritis. Our study enrolled 80 SLE patients with and without LN. Anti-nucleosome antibodies were elicited in $49(61.25 \%)$ patients, $24(60 \%)$ in group I and in $25(62.5 \%)$ in group II $(p=0.818)$ with a non-statistically significant difference between both groups. Although, some investigators suggest that anti-nucleosome antibodies are more likely to be detected in patients with nephritis and may serve as a useful biomarker in the diagnosis of active LN [24-26], our

Table 7 Multivariate analysis of factors associated with lupus nephritis

\begin{tabular}{llll}
\hline Risk Factors & \multicolumn{2}{l}{ Relative Risk } & P value \\
\cline { 2 - 3 } & OR & $\mathrm{Cl}(95 \%)$ & \\
\hline Low C4 & 14.04 & $(2.97-66.43)$ & $<0.001$ \\
Low C3 & 5.57 & $(2.12-14.65)$ & $<0.001$ \\
Anti-C1q antibody & 3.60 & $(1.40-9.10)$ & 0.007 \\
Anti-nucleosome antibody & 0.90 & $(0.37-2.21)$ & 0.818 \\
\hline
\end{tabular}

OR: Odds ratio, Cl: Confidence interval study was unable to confirm this association. In agreement with our findings, several authors showed that anti-nucleosome antibodies have a limited value in distinguishing SLE patients with or without active nephritis $[15,17,27-29]$. Furthermore, data from a meta-analysis conducted on 26 articles showed that anti-nucleosome antibody didn't correlate with kidney involvement in SLE, but was significantly associated with disease activity measured by the international score systems [30]. Identification of patients with active SLE is anchored on the presence of clinical symptoms, with compatible serological abnormalities reinforcing the clinical impression. Several reports have addressed the utility of anti-nucleosome antibodies to monitor disease activity with varying findings. In our study, disease activity as assessed by ECLAM score was not mirrored by the presence of anti-nucleosome antibody. Furthermore, anti-nucleosome antibodies were not associated with laboratory features that signify active disease as elevated ESR, low C3, low C4, \& low albumin. This conclusion was consistent with other studies [15, 31-34].

Our study was able to support the association of anti-C1q antibody and the development of LN. Anti-C1q antibody was detected in 34 (42.5\%) patients, 
$23(67.6 \%)$ were in group I and $11(62.5 \%)$ in group II and this difference was statistically significant $(p<0.001)$. After a multivariate analysis in our patients, positive anti-C1q antibody has been isolated as a statistically significant risk factor for developing lupus nephritis $(\mathrm{OR}=3.60, p=0.007)$. Anti-C1q antibodies were also associated laboratory markers of active disease as elevated $\operatorname{ESR}(p=0.015)$, low serum albumin $(p=0.009)$ and low levels of C3 $(p=0.033)$ and C4 $(p=0.037)$. Several studies demonstrate a strong correlation between the presence of anti-C1q antibodies and lupus nephritis, and suggest that anti-C1q determination may serve as a noninvasive biomarker to monitor renal involvement and/or predict renal flares [11-13, 35]. On the other hand, Katsumata and colleagues demonstrated that antibodies to $\mathrm{C} 1 \mathrm{q}$ were associated with global activity of SLE but not specifically with active LN [36]. In a review of 28 studies measuring anti-C1q antibodies to detect a history of LN in SLE patients and 9 studies in which anti-C1q was measured to distinguish between active and inactive LN, they suggested that the measurement of anti-C1q auto-antibodies as a 'stand-alone' biomarker is not diagnostically useful [37] The variability reported in different studies for anti-C1q antibody could be in part attributed to differences in classes of nephropathy, the time of serum sample and methodological differences in the commercial ELISA kits used.

In spite of a growing number of reports on the study of anti-nucleosome and anti-C1q antibodies, only few studies focus on the simultaneous presence of both antibodies. In the current study, double positivity of anti-nucleosome and anti-C1q antibodies was found in $22(27.5 \%)$ patients. In an effort to explore the relationship between double positive antibodies and different disease manifestations, a statistically significant association was found with vasculitis $(p=0.016)$. To date, no studies have investigated the association between double positive antibodies (anti-nucleosome and anti-C1q) and clinical features in SLE patients. Regarding the relationship between double positive antibodies and laboratory findings, our study showed that patients with double positive antibodies have a significantly higher disease activity as assessed by ECLAM score, elevated ESR, lower serum albumin and low C3 levels. Our findings parallel those of other authors [38, 39].

As this study did not investigate the relationship between longitudinal changes in disease activity and autoantibody titres in individual patients, detection of alterations in antibodies with clinically significant changes might have been masked by a predominance of individuals with no change in disease activity or a balance between individuals with flaring and remitting disease. We suggest that longitudinal tracking of biomarkers and disease activity may be more useful for updating clinical decisions at the time of assessment than forecasting flares.

\section{Conclusions}

In conclusion, presence of anti-C1q antibody is associated with the risk of developing LN; however, further, larger prospective studies are warranted to clarify and evaluate the specificity and predictive value of anti-C1q antibodies as a non-invasive biomarker of active $\mathrm{LN}$ to help in early identification of patients at risk whom would be eligible for early intense immunosuppressive treatment.

\section{Funding \\ No source of funding. The study was carried out on the investigators own expenses.}

\section{Availability of data and materials}

Please contact author for data requests.

\section{Authors' contributions}

IMMetwally Study design; Elaboration of the article and critical review; Data analysis and interpretation. NNEesa Elaboration of the article and critical revision; Data analysis and interpretation. MHYacoub Laboratory workup. RMElsman; Study design; Data collection; Data analysis and interpretation; Manuscript preparation. All authors read and approved the final manuscript to be published.

\section{Ethics approval and consent to participate}

All studies on humans described in this manuscript were carried out with the approval of the ethics committee of Cairo University, Faculty of medicine and in accordance with national and the Helsinki Declaration of 1975 (in its current revised form).

All individual participants included in the study were informed about the aim of the study and gave their informed consent for participation \& publication.

Consent for publication

All authors consent to publish the manuscript in Advances in Rheumatology.

Competing interests

I.M.Metwally, N.N.Eesa, M.H.Yacoub \& R.M.Elsman declare that they have no competing interests.

\section{Publisher's Note}

Springer Nature remains neutral with regard to jurisdictional claims in published maps and institutional affiliations.

\section{Author details}

${ }^{1}$ Rheumatology and Rehabilitation Department, Faculty of Medicine, Cairo University, Cairo, Egypt. ${ }^{2}$ Clinical and Chemical Pathology Department, Faculty of Medicine, Cairo University, Cairo, Egypt. ${ }^{3}$ Rheumatology Department, Helwan University Hospital, Helwan, Egypt.

Received: 25 May 2018 Accepted: 21 February 2019

Published online: 04 March 2019

References

1. Korbet SM, Lewis EJ, SchwartzMM. Factors predictive of outcome in severe lupus nephritis Lupus Nephritis Collaborative Study Group. Am J Kidney Dis 2000; 35:904-914.

2. Esdaile JM, Joseph L, MacKenzie T, Kashgarian M, Hayslett JP. The benefit of early treatment with immunosuppressive agents in lupus nephritis. J Rheumatol. 1994:21:2046-51.

3. Illei GG, Tackey E, Lapteva L, Lipsky PE. Biomarkers in systemic lupus erythematosus: II. Markers of disease activity. Arthritis Rheum. 2004;50:204865. 
4. Schwartz N, Michaelson JS, Putterman C. Lipocalin-2, TWEAK, and other cytokines as urinary biomarkers for lupus nephritis. Ann N Y Acad Sci. 2007; 1109:265-74.

5. Haładyj E, Cervera R. Do we still need renal biopsy in lupus nephritis? Reumatologia. 2016;54(2):61-6.

6. Song D, Wu LH, Wang FM, Yang XW, Zhu D, Chen M, et al. The spectrum of renal thrombotic microangiopathy in lupus nephritis. Arthritis Res Ther. 2013;15(1):R12.

7. Salem A, Alexa M, Brad HR. Update on lupus nephritis. CJASN. 2017;12:825-35.

8. Fiehn C, Hajjar Y, Mueller K, Waldherr R, Ho AD, Andrassy K. Improved clinical outcome of lupus nephritis during the past decade: importance of early diagnosis and treatment. Ann Rheum Dis. 2003;62:435-9.

9. Houssiau FA, Vasconcelos C, D'Cruz D, Sebastiani GD, Garrido ER, Danieli MG, et al. Early response to immunosuppressive therapy predicts good renal outcome in lupus nephritis. Arthritis Rheum. 2004;50:3934-40.

10. Karim Y, Yong F, Cruz P. Importance of autoantibodies in lupus nephritis. Expert Rev Clin Immunol. 2007;3(6):937-47.

11. Bock M, Heijnen I, Trendelenburg M. Anti-C1q antibodies as a follow-up marker in SLE patients. PLoS One 2015;16: 10(4): e0123572.

12. Trendelenburg M. Antibodies against C1q in patients with systemic lupus erythematosus. Springer Semin Immunopathol. 2005;27:276-85.

13. Siegert CE, Daha MR, Tseng CM, Coremans IE, van Es LA, Breedveld FC. Predictive value of IgG autoantibodies against C1q for nephritis in systemic lupus erythematosus. Ann Rheum Dis. 1993;52(12):851-6.

14. Moura CG, Lima I, Barbosa L, Athanazio D, Reis E, Reis M, et al. Anti-C1q antibodies: association with nephritis and disease activity in systemic lupus erythematosus. J Clin Lab Anal. 2009;23(1):19-23.

15. Saigal R, Goyal L, Agrawal A, Mehta A, Mittal P, Yadav R, et al. Antinucleosome antibodies in patients with systemic lupus erythematosus : potential utility as a diagnostic tool and disease activity marker and its comparison with anti-dsDNA antibody. J Assoc Physicians India. 2013;61(6): 372-7.

16. Shao WH, Cohen PL. Disturbances of apoptotic cell clearance in systemic lupus erythematosus. Arthritis Res Ther. 2011;13(1):202.

17. Bigler C, Lopez-Trascasa M, Potlukova E, Moll S, Danner D, Schaller M. Antinucleosome antibodies as a marker of active proliferative lupus nephritis. Am J Kidney Dis. 2008;51:624-9.

18. Hochberg MC. Updating the American College of Rheumatology revised criteria for the classification of systemic lupus erythematosus. Arthritis Rheum. 1997:40(9):1725.

19. Walport J, Davies A, Botto M. C1q and systemic lupus erythematosus. Immunobiology. 1998;199:265-85.

20. Amital H, Shoenfeld Y, Nucleosomes DNA. SLE: where is the starting point? Clin Exp Rheumatol. 1996;14(5):475-7.

21. Weening JJ, D'Agati VD, Schwartz MM, Seshan SV, Alpers CE, Appel GB, et al. International Society of Nephrology Working Group on the classification of lupus nephritis and Renal Pathology Society working group on the classification of lupus nephritis: classification of glomerulonephritis in systemic lupus erythematosus revised. Kidney Int. 2004;65(5):521-30.

22. Vitali C, Bencivelli W, Isenberg D, Smolen J, Snaith M, Sciuto M, et al. Disease activity in systemic lupus erythematosus: report of the consensus study Group of the European Workshop for rheumatology research. II. Identification of the variables indicative of disease activity and their use in the development of an activity score. Clin Exp Rheuma. 1992;10(5):541-7.

23. Moroni G, Quaglini S, Radice A, Trezzi B, Raffiotta F, Messa P, et al. The value of a panel of autoantibodies for predicting the activity of lupus nephritis at time of renal biopsy. J Immunol Res. 2015;2015:8.

24. Cervera R, Vinas O, Ramos-Casals M, Font J, Garcia-Carrasco M, Siso A. Antichromatin antibodies in systemic lupus erythematosus: a useful marker for lupus nephropathy. Ann Rheum Dis. 2003;62(5):431-4.

25. Gutierrez-Adrianzen O, Koutouzov S, Mota R, das Chagas Medeiros M, Bach J, de Holanda Campos H. Diagnostic value of anti-nucleosome antibodies in the assessment of disease activity of systemic lupus erythematosus: a prospective study comparing anti-nucleosome with anti-dsDNA antibodies. J Rheumatol. 2006;33:1538-44.

26. Haddouk S, Ben Ayed M, Baklouti S, Hachicha J, Bahloul Z, Masmoudi H. Clinical significance of anti-nucleosome antibodies in Tunisian systemic lupus erythematosus patients. Clin Rheumatol. 2005;24:219-22.

27. Liu C, Kao A, Manzi S, Ahearn J. Biomarkers in systemic lupus erythematosus: challenges and prospects for the future. Ther Adv Musculoskelet Dis. 2013;5(4):210-33.
28. Quattrocchi P, Barrile A, Bonanno D, Giannetto L, Patafi M, Tigano V, et al. Anti-nucleosome antibodies in SLE. Reumatismo. 2005:57:109-13.

29. Bose N, Wang X, Gupta M, Yao Q. The clinical utility of anti-chromatin antibodies as measured by BioPlex 2200 in the diagnosis of systemic lupus erythematosus versus other rheumatic diseases. Int J Clin Exp Med. 2012;5: $316-20$.

30. Bizzaro N, Villalta D, Giavarina D, Tozzoli R. Are anti-nucleosome antibodies a better diagnostic marker than anti-dsDNA antibodies for systemic lupus erythematosus? A systematic review and a study of metanalysis. Autoimmun Rev. 2012;12(2):97-106.

31. El Desouky S, El-Gazzar I, Rashed L, Salama N. Correlation between various clinical parameters of systemic lupus erythematosus and levels of antihistone and anti-chromatin antibodies. The Egyptian Rheumatologist. 2015; 37:97-104.

32. Su Y, Jia R, Han L, Li Z. Role of anti-nucleosome antibodyin the diagnosis of systemic lupus erythematosus. Clin Immunol. 2007;122(1):115-20.

33. Sardeto G, Simas L, Skare T, Nishiara R, Utiyama S. Antinucleosome in systemic lupus erythematosus. A study in a Brazilian population. Clin Rheumatol. 2012;31:553-6.

34. Manson J, Ma A, Rogers P, Berden H, van der Vlag J, D'Cruz P, et al. Relationship between anti-dsDNA, anti-nucleosome and anti-alpha-actinin antibodies and markers of renal disease in patients with lupus nephritis: a prospective longitudinal study. Arthritis Res Ther. 2009;11(5):154

35. Sinico R, Rimoldi L, Radice A, Bianchi L, Gallelli B, Moroni G. Anti-C1q autoantibodies in lupus nephritis. Ann N Y Acad Sci. 2009;1173:47-51.

36. Katsumata Y, Miyake K, Kawaguchi Y, Okamoto Y, Kawamoto M, Gono T, et al. Anti-C1q antibodies are associated with systemic lupus erythematosus global activity but not specifically with nephritis: a controlled study of 126 consecutive patients. Arthritis Rheum. 2011;63(8):2436-44.

37. Eggleton P, Ukoumunne OC, Cottrell I, Khan A, Maqsood S, Thornes J, et al. Autoantibodies against C1q as a diagnostic measure of lupus nephritis: systematic review and meta-analysis. J Clin Cell Immunol. 2014;5(2):210.

38. Chen Z, Wang G, Wang G, Li X. Anti-C1q antibody is a valuable biological marker for prediction of renal pathological characteristics in lupus nephritis. Clin Rheumatol. 2012;31:1323-9.

39. Živković V, Aleksandra Stanković1, Tatjana Cvetković2, Branka Mitić2, Svetislav Kostić2, Jovan Nedović1, et al. Anti-dsDNA, anti-nucleosome and anti-C1q antibodies as disease activity markers in patients with systemic lupus erythematosus. Srp Arh Celok Lek 2014; 142 (7-8): 431-436.

\section{Ready to submit your research? Choose BMC and benefit from:}

- fast, convenient online submission

- thorough peer review by experienced researchers in your field

- rapid publication on acceptance

- support for research data, including large and complex data types

- gold Open Access which fosters wider collaboration and increased citations

- maximum visibility for your research: over $100 \mathrm{M}$ website views per year

At $\mathrm{BMC}$, research is always in progress.

Learn more biomedcentral.com/submission 